\title{
Camptodactyly syndrome, Guadalajara type 1
}

INSERM

\section{Source}

INSERM. (1999). Orphanet: an online rare disease and orphan drug data base.

Camptodactyly syndrome, Guadalajara type 1. ORPHA:1327

Camptodactyly syndrome, Guadalajara type 1 is a rare syndrome consisting of growth retardation, facial dysmorphism, camptodactyly and skeletal anomalies. 